\title{
Study of Agricultural Informatization Standards Framework
}

\author{
Yunpeng Cui, Shihong Liu, and Pengju He \\ Key Laboratory of Digital Agricultural Early-warning Technology, \\ Ministry of Agriculture, Beijing, The People's Republic of China 100081
}

\begin{abstract}
This paper introduces the research methods, the content and technical route about the study of agricultural informatization standards Framework, which describes the structure of the agricultural informatization standard system, the construction process of agricultural informatization standard system diagram, and put forward the working ideas and deployment of the future standardization work of agricultural informatization. Finally, the paper put forward that the standardization of agricultural informatization is the necessary route for the construction and development of agricultural informatization, it's significant for the construction of agricultural informatization in China.
\end{abstract}

Keywords: Standards Framework, Agricultural Informatization.

\section{Introduction}

To strengthen the construction of agricultural informatization is very important for China's agriculture development and upgrading. In recent years, China has made significant progress in agriculture informatization construction, on the other hand, because the lack of overall planning and related standards, the construction can't develop orderly and formally ${ }^{[1]}$. Therefore, to speed up the process of agricultural informatization standardization is an important measure for ensuring the progress of china's agricultural informatization ${ }^{[2]}$.

Against the background, commissioned by the market economic information department of MOA, PRC, the agriculture information institute of CAAS start the agriculture informatization standards system study, the purpose of the study is coordinate and deploy the agriculture informatization standardization work, sort out existed national and domestic agriculture informatization standards, and promote the agriculture informatization standardization process, ensuring the development of the agriculture informatization.

\section{Agriculture Informatization Standardization System Reference Model}

The reference model of agriculture informatization standardization system shows as Figure 1. The agriculture informatization standards can be divided into three categories 
according to their usage ${ }^{[3]}$, basic standards, universal standards and specialized standards, among the three kinds of standards, the management standards, the technical standards and the working standards spread over all these standards. The management standards are used in the management of the agriculture informatization work, which standardize the management of agriculture informatization construction; while the technical standards regulate the technical details involved in the process of the implementation of agriculture informatization; the work standards standardize and restrain the concrete work of the development and implementation of agriculture informatization.

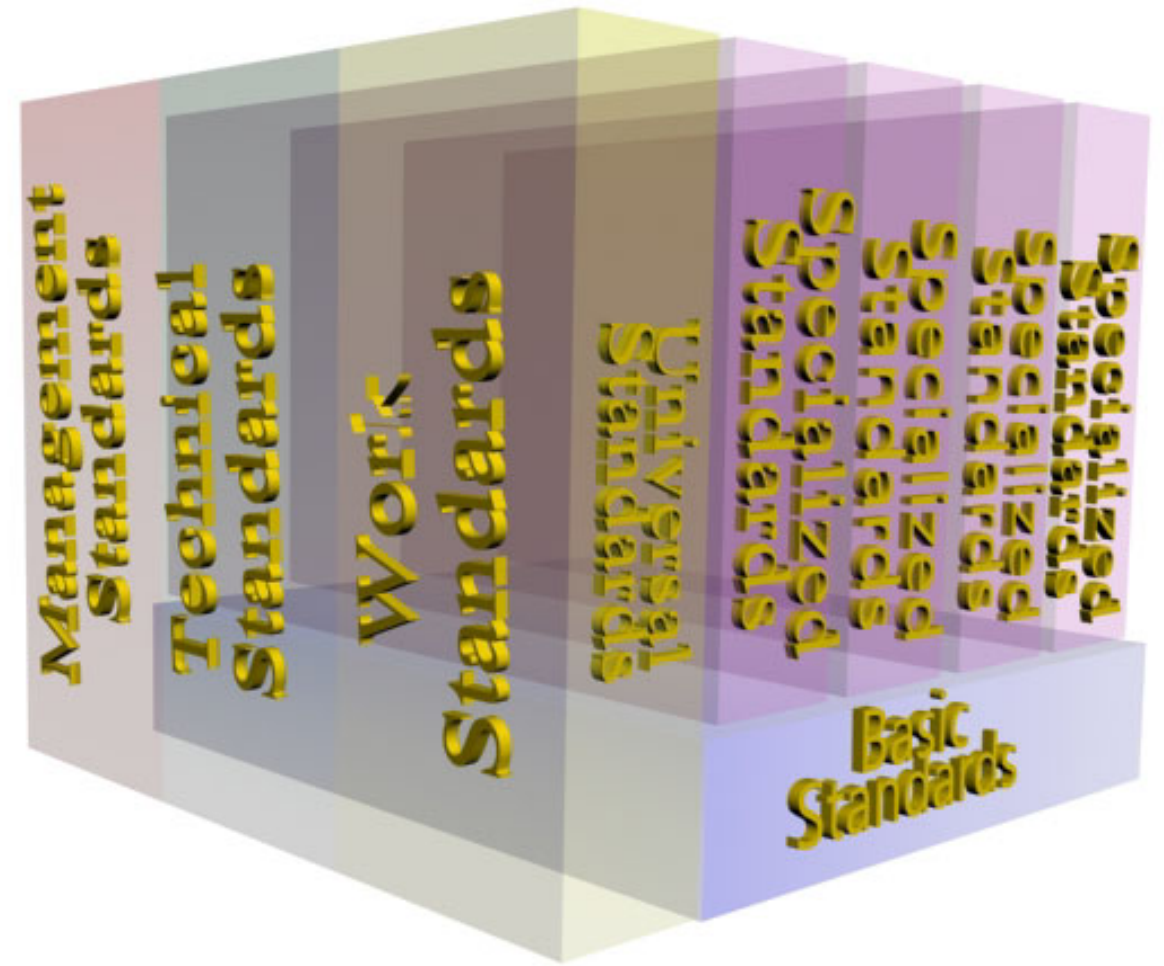

Fig. 1. The reference model of agriculture informatization standardization system

\section{The Agriculture Informatization Standards System Framework and Standards System Table}

The thoughts we construct the agriculture informatization standards system framework includes 2 methods, firstly, we use the three-dimensional standards system framework thoughts put forward by Dr. Verman ${ }^{[4]}$, to divide complex problems into easy sub tasks, and express the tasks with human thinking ways, so make the complex problems simplified and organized. 


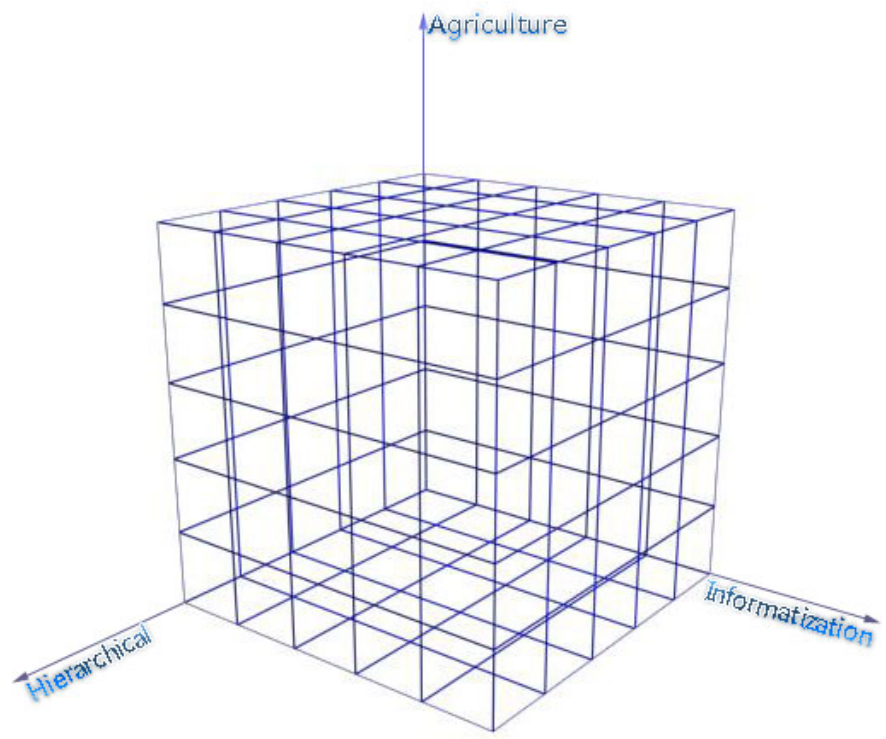

Fig. 2. The three-dimensional model of agriculture informatization factor categories

We divide all the agriculture information factors according to their categories, represent any 3 categories related closely with three-dimensional model (shown as Figure 2), then fill the every category with concrete factors , and combine the related factors, filter, analyze the combined factors, finally, produce the framework.

Secondly, through the top-down and bottom-up methods, top-down means extracting and summary of the existing taxonomy (such as FAO Agricultural subject classification scheme and Chinese library classification) to product the framework, and

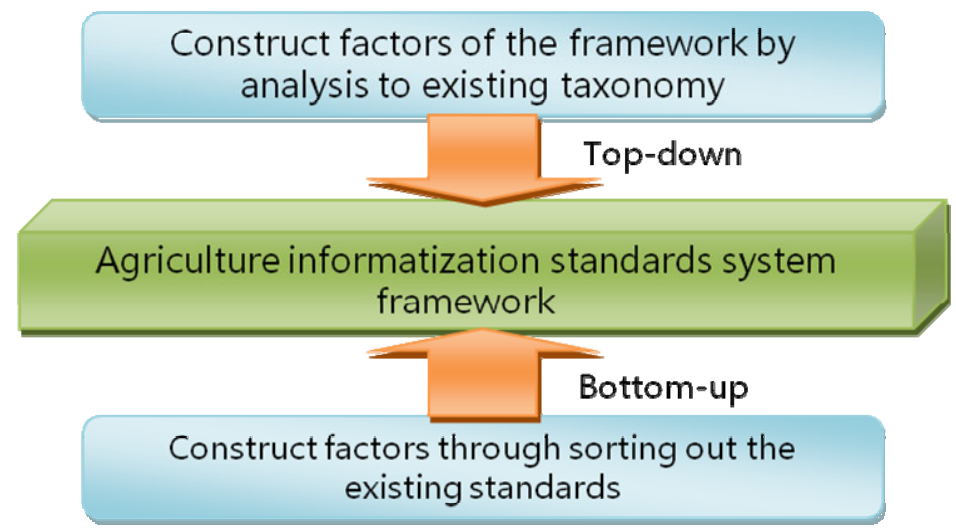

Fig. 3. The top-down and bottom-up methods for constructing the agriculture informatization standards system framework 


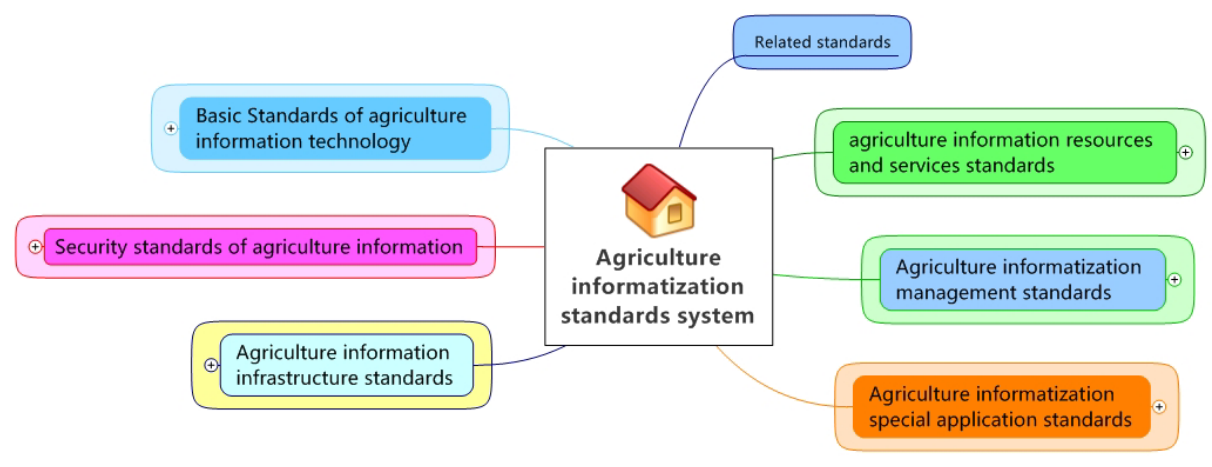

Fig. 4. The top layer of agriculture informatization standards framework

bottom-up means to sort out existing agriculture informatization standards and related standards to produce and verify the framework (see Figure 3).

Figure 4 shows the top layer of the agriculture informatization standards framework.

The agriculture informatization standards system framework is consist of 7 categories, they are related standards, basic standards of agriculture information technology, security standards of agriculture information, agriculture information infrastructure standards, agriculture information resources and services standards, agriculture informatization management standards and agriculture informatization special application standards.

We established an agriculture informatization standards system table based on the framework and the sorting out of the existing standards, now we have more than 2,000 standards in the table, include about 900 standards that haven't been formulated but necessary for agriculture informatization construction in our country.

\section{The Working Scheme of Agriculture Informatization Standards System Construction}

The whole work of the construction of agriculture informatization standards system is consist of 6 stages, system pre-research, system planning, standards formulation, standards trial and verification, standards training and carry out and standards application.

The task of pre-research stage includes analysis for the national and domestic agriculture informatization and standards, find the problems, trends of the construction of agriculture informatization in our country, ensure the background and purpose of the construction of agriculture informatization standards system. The study of the paper is a part of this stage.

At the system planning stage, the purpose and the responsible organization of the agriculture informatization standardization should be put forward clearly, and the system should be planned, the platform for standards study and formulation should be established. 
The task of standards formulation stage is the organizing of the concrete standards formulation. The basic standards should be formulated first, and then other standards. the agriculture informatization standardization working community should be established at this stage, to manage and coordinate the standards formulation work.

At the standards trial and verification stage, based on the work objectives, contents and application of object of last stage, the standards application and verification tools should be developed, to verify the applicability of the standards.

At standards training and carry out stage, the related organization should organize the training for relevant organizations and individuals, and organize the standards publicly and implementation work.

Finally, the standards application stage, the standards conformance certification mechanism and implementation mechanism should be established, the standards should be applied in the related product development and project completely, and constantly improve the agriculture informatization standards system and the specific standards based on the application.

\section{Conclusion}

The appearance of agriculture informatization standards system is the inevitable consequences of agriculture informatization construction ${ }^{[5]}$, and it's the basis of agriculture informatization technology system, it's also one of the key bottlenecks for agriculture informatization progress. The purpose of agriculture informatization standardization is to establish a series of agriculture informatization standards, the implementation of the standards can work together to support the planning of agriculture informatization and related project, guiding the development and innovation of agriculture information industry, ensure the development of construction of agriculture informatization in our country scientifically and orderly, and accelerate upgrading of agriculture information industry.

\section{Acknowledgement}

The research was supported by the special project from ministry of agriculture of the people's republic of China, named study of agriculture informatization standards system and special fund of basic commonweal research institute project of information institute of CAAS, and National $11^{\text {th }}$ five-year technology based plan topic named study of Agricultural product quantity Safety Data obtained standards (2009BADA9B02).

\section{References}

[1] Xie, X., Liu, X.: Study of Beijing agriculture standards system construction. China Standardization (7), 8-9 (2007)

[2] Liu, S., Hu, H.: Study on standard system frame of agriculture informatization. Agriculture Network Information (2), 13-17 (2006) 
[3] Jiang, Z., Yao, Y.: Reference model for information standards of land and resources. Geomatics World (5), 12-17 (2003)

[4] Verman, L.: Standardization-a New Discipline. Archon books, The Show String Press Inc. (1980)

[5] Yang, L.: Study of construction of national agriculture technical information classification and encoding standards system. China Standardization (12), 13-16 (2006) 